\title{
3
}

\section{Motive and Context}

If we don't clean up litter, it will be a long time before it disappears. The breakdown times for waste vary from several weeks to an eternity. Non-biological materials from conventional plastics to chewing gum do not decompose, but break apart into tiny particles that bioaccumulate in soil and water. MilieuCentraal, www.milieucentraal.nl

If we keep consuming the way we are now, by 2050 we'll need at least three planets to feed the entire world. A transition from animal to plant-based proteins is essential. Dutch WeedBurger, dutchweedburger.com

In 2050 there will be more plastic than fish in the sea. Ellen MacArthur Foundation, ellenmacarthurfoundation.org

A pair of jeans pollutes as much water as your body uses over ten years. Damselfly London, damselfylondon.com

All things considered, we have to go back to the circular thinking of the good old days, but with today's knowledge and insights. So, we are trying to design efficient production, at acceptable prices for the average consumer, and with attention to animal welfare, the environment, and the farmer. Kipster, www.kipster.nl

We see access to energy as a fundamental human right. To us, this is not an elusive goal, but an issue that requires immediate attention. It is a straightup precondition for further development, because access to electricity means access to education, to communication, to income-generating opportunities, to self-belief, and to a better future. WakaWaka, waka-waka.com 


\subsection{Exploring the Challenge and Opportunity}

When you start working on a new business model, the main question is: Why are you doing it? What problem, challenge, or opportunity have you identified within a specific (existing) context? You could think of the necessity of working in a $\mathrm{CO}_{2}$-neutral way or the increasing demand for modular elements in construction or electronics in the context of the transition to the circular economy. Or your business model could focus on improving biodiversity, abolishing single-use plastics, or making bikes from recycled materials. If the immediate reason and motive driving you to develop your business model is not clear, then this needs to be the first thing to consider. Building Block \# 1-Motive and Context deals with this aspect and is about capturing as clearly as possible the nature and context of the problem, the challenge, or the opportunity posed.

Slowly but surely, sustainability will become central to every business model. It follows logically that there will still be business ideas that are initially conventional (for conventional, read purely market-oriented). If this is the case for you/your team, it is important to use this building block to look carefully for the social and ecological components and the context of your idea. Which themes are playing a role? Which ones affect you the most and which ones can you use to turn the market opportunity into a social and ecological opportunity? In this way, you can expand your conventional reasoning and motivation into one in which sustainability is central, because that is what we are aiming for with future-oriented sustainable entrepreneurship: it is an integral part of your business model rather than something you do on the side.

What it is really about is developing a vision of what our food system will look like 30 years from now. Today's agriculture is based on ideas from 50 years ago: produce as much as possible at the lowest possible cost. We have gone overboard in that respect. Zanders (2020)

Everyone can identify reasonably quickly where the problems are in his or her environment, what bottlenecks exist, and where the shoe pinches. But one step further is to look for hidden opportunities. The idea of looking carefully at the context is essential here because this will steer the possibilities and choices that you have at a later stage of the development of the business model. There may also be real starting points within the context that you are looking at. Consider, for example, a municipality that wants to promote citizen participation, or a company that has a specific waste stream and has no current opportunities within its value chain to do anything with it. 
In everyday reality, the context within which we are operating is complex, ranging from the immediate environment to, for example, the sector or industry in which you are seeking to operate. What at first glance might have seemed self-evident and clear-cut is not always so. Add to this context the societal and macro-related issues, such as labour market developments in the coming decade, possible sectoral resource scarcity, or government ambitions such as circular agriculture or a circular economy by 2050 . At the same time, there are all sorts of institutional frameworks that impose constraints through legislation and regulations that you need to be aware of.

A motive to construct a new business model can also be very pragmatic, and this is certainly applicable to existing entrepreneurs. Consider, for example, a $\mathrm{CO}_{2}$ performance ladder which directs companies and their valuechains to reduce their $\mathrm{CO}_{2}$ footprint. Or the ambition of the EU to become a $\mathrm{CO}_{2}$-neutral continent by 2050. Many entrepreneurs do not focus on the transition itself, but want to respond to expected changes, developments of this kind in their markets, affiliated customer behaviours and the relevant institutional setting (e.g. rules and regulations to guide the ambitions).

\section{The Context of Everyday Normal}

People's habits and routines also play an important role in everyday activities-whether business or private. Much of what we do is done on autopilot-that's the way we always do it - and has been done that way for years. We are often symbolically stuck because habits are very comfortable and implicitly reflect the status quo of arrangements and agreements.

The fact that all these unstructured developments are dynamically changing complicates matters even further. It would be nice to be able to take a snapshot of the status quo, find a solution for it, and then put it back, but, unfortunately, that is not possible. Everything and everyone is on the move all the time. What is in the spotlight today is off tomorrow (but not resolved, if that is what you think). Problems change in nature and scope while you are looking at them and in the process your interpretation of them changes. Perhaps the issue you started looking at is not as interesting as it seemed in the beginning. Looking at a context with respect to its complexity is of the essence: not simplifying things or sweeping them under the rug, and trying your best to discover what truly matters, as well as where you see the opportunities to do something. Getting clear about what motivates you to start working on a specific issue is, after all, the basis for further shaping the business model. Sustainable business models take shape within the socially and economically quasi-stable context sketched above. 


\section{Important}

Purpose economy

If anything is characteristic of meaningful entrepreneurship, it is that purposeful entrepreneurs are mindful of the fact that the market is a fictional narrowing of reality. The market only exists in our minds. The real place of companies is not the market, but society and Mother Earth.

\subsection{Tools for Visualizing the Motive and the Context}

Even if you intuitively understand your motive and context, it is both prudent and can be advantageous to make a slightly more thorough analysis and to make both explicit. Using multiple different instruments to perform this analysis should help you to obtain a clearer and more nuanced view of the current situation. We recommend that you conduct more than one. After all, instruments are lenses which will reveal different aspects of the same issue. For this purpose, we propose several groups of instruments which could be a useful resource, with the caveat that we cannot vouch for the theoretical foundation or methodical quality of the instruments and advise that any instruments should be handled critically, since all tools have inherent blind spots.

(a) A quick scan of facts:The simplest method is to gather facts about the issue you want to address and organize them properly. For instance, you could start with a basic internet search and see what information comes up when you enter some fairly random keywords. For fun, also look at the rising or falling popularity of the issue via, for example, Google Citations. Make sure that you also use proper sources from reputable institutions. In the Netherlands, these include the Central Bureau of Statistics (CBS), the Netherlands Environmental Assessment Agency (PBL), or most government websites. In the UK, you can use the Office for National Statistics (ONS). In addition, the European Commission provides a large database of reputable publications on a wide range of topics. Supplement this with scientific publications and research reports from credible commercial institutions. We do not recommend relying on the popular media (digital or in print). Whatever you do, always use multiple sources so that you can compare and cross-check assumptions 
and figures. Make sure that you note the source references and above all ensure that you separate facts from opinions.

(b) Macro-analyses like DESTEP and SWOT: The DESTEP analysis, also called the PEST analysis, is an analytical framework to map the Demographic, Economic, Social, Technological, Ecological, and Political factors at the macro-environmental level. These are six perspectives (variables) that together produce a picture of the macro-economic environment of a company or organization. Combined, they give insight into the elements around a market that cannot be influenced directly. The aim is to gain insight into the short- and long-term impacts of these factors. There are dozens of (public) sources that help you to carry out a DESTEP analysis in a neat and methodological manner. The so-called SWOT analysis-SWOT stands for Strengths, Weaknesses, Opportunities, and Threats-is a complementary analysis to a DESTEP analysis. The SWOT is a tool that creates a structured representation of an organization's perspective of internal strengths and weaknesses relative to perceived information in the analysis. A crucial benefit of this analysis is the confrontation matrix, in which you develop insight into the relationship between your plan and the market or context. Again, a multitude of tools, instructional videos, and canvasses can be found online.

(c) Life cycle analysis: Life cycle analysis (LCA) shows the environmental impact during the various life stages of a product. This can also be applied to a chain, a loop, or an (entire) organization. An LCA is also referred to as a cradle-to-grave analysis because it covers the whole process from the extraction of the necessary raw materials, to production, transport, use, and waste processing. The LCA was first used in the 1980s. It is based on a closed process that provides insight into the use of energy and materials as well as pollutants and emissions into the environment in all stages of its life cycle. The process helps to identify where in the product's lifespan the impact is strongest and where opportunities exist for sustainable improvements. Thinking about LCAs has been methodically developed to a great extent. For example, the International Organization for Standardization (ISO) has developed a standard for LCA: the ISO 14040 series. The continued use of the LCA is evident from the UN's Life Cycle Initiative (see: www.lifecycleinitia tive.org) and the European counterpart the European Platform on Life Cycle Assessment (see: eplca.jrc.ec.europa.eu/LCDN). Consultancy agencies or research institutes can do extensive LCAs, but possibilities exist to perform a simple LCA yourself to get an initial idea (do an internet search for $L C A$ tool). 
(d) Trend analysis \& scenarios: The so-called trend analysis is a different ballgame. This involves extending specific trends into the future, for example, for a period of five or ten years. What the future will bring appeals to the imagination and is instrumental in determining the market. Of course, there is also such a thing as trendology, and there are quite a few professional forecasters, but those who look at the matter seriously end up with scenarios and scenario planning. Scenarios are useful instruments for developing and exploring different future possibilities. In short, a scenario is a chronological description of a particular event that has taken place or is yet to take place. Shell developed the scenario methodology in the 1980s. Their definition is 'Scenarios are not predictions of the future. They are stories about how the future might look and are underpinned by models that provide the backbone logic and rigor to these future possibilities' (Shell, 2017a). Their methodology is open to the public. Check out Shell's accompanying website (Shell, 2017b) for an impression.

(e) Environmental analysis:Anyone who looks into the multitude of instruments and methods for making an environmental analysis will soon no longer be able to see the forest for the trees. Below, in random order, is a brief (and incomplete) list in addition to DESTEP, SWOT, LCA, and Scenario Methodology:

- Blue Ocean strategy

- brainstorming techniques

- capabilities analysis

- competition analysis

- need finding

- stage-gate

- open-space

- five forces model

- value proposition canvas.

And this is just the tip of the iceberg. So, whatever you choose and whatever combination you make, keep a close eye on why you are doing this analysis, because the available tools are only tools.

\subsection{Case Studies: Motive and Context}

Below are three short case studies that each address the motives and context in which a business model can emerge. 


\section{Case study: $\mathrm{CO}_{2}$}

Greenhouse gases are a natural phenomenon in the atmosphere, but human actions, such as the large-scale burning of fossil fuels and forest clearing, have caused far more greenhouse gases to be released into the atmosphere than the planet can naturally adapt to. The increase in these greenhouse gases, especially the enormous increase in $\mathrm{CO}_{2}$ from burning fossil fuels, is causing global warming. There is a clear correlation between the demonstrated temperature rise and the increased $\mathrm{CO}_{2}$ concentration in the atmosphere. The earth's temperature is expected to rise by 1.4-5.8 degrees if the way products are made and utilized does not change. Such an increase in $\mathrm{CO}_{2}$ will cause major problems. Think, for example, of rising sea levels, droughts, heatwaves, and ocean acidification. The high $\mathrm{CO}_{2}$ concentration is not the only cause of climate change. Methane gas, emitted by sources such as cows, and various minerals in manure and the associated nitrogen, phosphates, and ammonia that leak into the groundwater are also causing an ever-increasing problem. Farmers cannot get rid of their manure and are left with a surplus. They are obliged to process this surplus, for example by burning it, having it processed into fertilizer, or treating it to make dried digestate (Woltjer \& Smits, 2019). In recent years, more and more companies have begun to take measures to reduce $\mathrm{CO}_{2}$ emissions or to remove $\mathrm{CO}_{2}$ from the atmosphere and use it for other purposes, such as biofuel, growing plants, or insulation. The latter concept is also called Carbon Capture and Utilization. In this concept, $\mathrm{CO}_{2}$ is regarded as a renewable resource for the replacement of or an alternative to virgin raw materials. Instead of storing carbon dioxide, using it to produce valuable chemicals, materials, and fuels might be a better long-term solution (Al-Mamoori et al., 2017). The question remains as to what applications are most suitable for $\mathrm{CO}_{2}$. For example, it can be used for growing vegetables, soft fruits, flowers, and plants, especially in the summer and autumn, but also for producing fuel or as an additive in concrete.

\section{Case study: Mixed plastics}

How we are currently dealing with raw materials is not effective or sustainable economically, ecologically, and socially. The EU has recognized the need for waste regarded as resources in the 2020 Circular Economy Action Plan (CEAP 2.0). In a sense, most EU countries are doing fairly well with such materials as paper and glass. However, we do have a problem with the handling of plastics. Plastic is predominantly used only once (referred to as single-use plastic) and is regarded as waste rather than a raw material from which new products can be made. Addressing this issue requires identification of alternative substitutes for single-use applications: developing better systems for the collection and recovery of plastics and the utilization of fewer mixed plastics in packaging, as well as developing more products from recycled plastic. Despite the many improvements made so far, most municipal recycling systems are still far from circular. In the Netherlands, for example, around $26-30 \%$ of the sorted plastic ends up as residual waste (Jetten et al., 2011). A large part of this is mixed 
plastic and consists of a wide variety of plastics such as polypropylene, polybutene, polystyrene, and polyethylene terephthalate, the latter better known as PET. Moreover, this waste flow tends to be mixed with things like organic material, sand, metals, glass, and paper. Currently, it is still too difficult to filter out the mono-flows. Therefore, the residue is burned. We need to find an innovative way to save the still-usable substances in residual waste (Bergsma et al., 2011; Jetten et al., 2011).

\section{Case study: Plastic caps}

Every year more than $\mathbf{3 0 0}$ million tons of plastic products are produced worldwide. Many of these products have a short life cycle, and the vast majority are single use only. In 2018 some 86 tons of plastic found its way into the oceans (Plastic Soup Foundation, n.d.). WasteBoards (wasteboards.com) wants to change this and has developed a product that highlights both the problem (plastic that ends up as litter) and offers a beautiful solution (skateboards made from plastic caps). With a so-called bakery, they produce high-quality skateboards with a considerably smaller environmental impact than that of regular skateboards. The skateboards have been on the market for several years now. However, it is a fairly labour-intensive production process for a small niche market. Furthermore, the considerable amount of plastic in the oceans exceeds the demand for skateboards by far, motivating WasteBoards to explore and develop new products, addressing new markets. A key requirement for Wasteboards is that any new products they develop can be produced anywhere in the world on a relatively large scale: they should be products that many people want to have and can be made by melting plastic caps.

\subsection{In Conclusion}

These three cases illustrate that the motives and the context for getting started with a particular issue can be completely different. These examples also show that perhaps everything and anything can be the reason to start working on a business model. This is stimulating, on the one hand, but also a bit overwhelming on the other. For it suggests that we live in a world where new problems are constantly emerging, which may become increasingly difficult to solve due to their complexity. 


\section{References}

Al-Mamoori, A., Krishnamurthy, A., Rownaghi, A. A., \& Rezaei, F. (2017). Carbon capture and utilization update. Energy Technology, 5, 834-849. https://doi.org/10. 1002/ente.201600747.

Bergsma, G., Bijleveld, M., Otten, M., \& Krutwagen, B. (2011). LCA: recycling of household plastic packaging waste (Final report 11.2430.79). CE Delft. www.ce. $\mathrm{nl} /$ publicatie/lca:_recycling_of_household_plastic_packaging_waste_/1208.

Ellen MacArthur Foundation. (2012). Towards the circular economy Vol. 1: Economic and business rationale for an accelerated transition (p. 98). Ellen Mac Arthur Foundation. www.ellenmacarthurfoundation.org/assets/downloads/publications/EllenMacArthur-Foundation-Towards-the-Circular-Economy-vol.1.pdf.

Jetten, L., Merkx, B., Krebbekx, J., \& Duivenvoorde, G. (2011). Onderzoek kunststof afdankstromen in Nederland. Berenschot Groep B.V. www.rvo.nl/sites/ default/files/bijlagen/Onderzoek\%20kunststof\%20afdankstromen $\% 20$ in $\% 20 \mathrm{~N}$ ederland\%20-\%20December\%202011.pdf.

Plastic Soup Foundation. (n.d.). Retrieved on 20 February 2020 from: www.plasti csoupfoundation.org/plastic-probleem/feiten-en-cijfers/plasticcijfers.

Shell. (2017a). Windows on the future: Modelling scenarios [YouTube]. Retrieved on 24 September 2020 from: youtu.be/14MDcGYif4k.

Shell. (2017b). Shell scenarios. Retrieved on 24 September 2020 from: www.shell. com/energy-and-innovation/the-energy-future/scenarios.html.

Woltjer, G., \& Smits, M.-J. (2019). De betekenis van mestverwerking in een circulaire economie (No. 2019-029). Wageningen Economic Research. library.wur.nl/Web Query/wurpubs/fulltext/475439.

Zanders, R. (2020). De 'groenste' kippenstal ter wereld: Beuningen is klaar voor een milieu-revolutie. Volkskrant. Retrieved on 20 February 2020 from: www.volkskrant.nl/nieuws-achtergrond/de-groenste-kippenstal-ter-wereldbeuningen-is-klaar-voor-een-milieurevolutie-b9f50166/. 
Open Access This chapter is licensed under the terms of the Creative Commons Attribution 4.0 International License (http://creativecommons.org/licenses/by/4.0/), which permits use, sharing, adaptation, distribution and reproduction in any medium or format, as long as you give appropriate credit to the original author(s) and the source, provide a link to the Creative Commons license and indicate if changes were made.

The images or other third party material in this chapter are included in the chapter's Creative Commons license, unless indicated otherwise in a credit line to the material. If material is not included in the chapter's Creative Commons license and your intended use is not permitted by statutory regulation or exceeds the permitted use, you will need to obtain permission directly from the copyright holder. 